\title{
ABSTRACTS OF COMMUNICATIONS Proceedings of the Thirty-fifth Meeting of the Agricultural Research Modellers' Group
}

\author{
EDITED BY \\ J. FRANCE AND L. A. CROMPTON \\ University of Reading, School of Agriculture, Policy and Development, Whiteknights, \\ Reading RG6 6AR, UK
}

This group, which is concerned with the applications of mathematics to agricultural science, was formed in 1970 and has since met at approximately yearly intervals in London for one-day meetings. The thirty-fifth meeting of the group, chaired by Dr David Parsons of Silsoe Research Institute, was held in the Kohn Centre at the Royal Society, 6 Carlton House Terrace, London on Friday, 11 April 2003 when the following papers were read.

Crop growth modelling for use with large-area input data. A. J. CHALLINOR ${ }^{1,2}$, T. R. WHEELER ${ }^{2}$, P. Q. CRAUFURD ${ }^{2}$, J. M. SLINGO ${ }^{1}$ AND D. I. F. GRIMES ${ }^{1} .{ }^{1}$ Department of Meteorology and ${ }^{2}$ Department of Agriculture, University of Reading, Reading RG6 6BB, UK

Numerical weather simulation models typically operate on spatial scales of the order of tens to hundreds of kilometres. This is many times greater than the field scale at which most crop simulation models operate. This disparity in spatial scale can be bridged either by downscaling weather data or upscaling the crop model. A study by Challinor et al. (2003) has shown that a $2.5 \times 2.5$ degree grid is an appropriate spatial scale for modelling groundnut yield in India when using numerical weather simulation output as input to the crop model.

Accordingly, a crop model has been developed to operate on such large spatial scales. The General Large-Area Model for annual crops (GLAM) is sufficiently process-based to simulate crop productivity over a range of tropical environments, whilst being simple enough to avoid the need for large amounts of location-specific input data or calibration. In this way, the model aims to combine the benefits of more empirical modelling methods (low input data requirement, validity over large areas) with the benefits of a process-based approach (the potential to capture variability due to different intra-seasonal weather patterns, and hence increased validity under future climates). The model is intended for any annual crop, and uses crop parameters that can be estimated from the literature. It is intended for use with any input data on a scale far greater than the field scale. In addition to numerical weather simulation models, GLAM can be used with remotely sensed data.

The model has been assessed using gridded simulations of groundnut yield across India for the period 1966-1989. Optimal values of model parameters were stable across space and time. Spatial variability in management is achieved though a single parameter. Aggregated all-India yields are well-correlated $(r=0.76)$ with national statistics, and the root mean square error is $8.4 \%$ of the mean yield.

This research was funded by the University of Reading Research Endowment Trust Fund.

Challinor, A. J., Slingo, J. M., Wheeler, T. R., Craufurd, P. Q. \& Grimes, D. I. F. (2003). Towards a combined seasonal weather and crop productivity forecasting system: determination of the spatial correlation scale. Journal of Applied Meteorology 42, 175-192.

An automatic growth and nutrition control system for broiler production. K. F. STACEY ${ }^{1}$, D. J. PARSONS ${ }^{1}$, A. R. FROST ${ }^{1}$, C. FISHER ${ }^{2}$, D. FILMER $^{3}$ AND A. FOTHERGILL ${ }^{4}{ }^{1}$ Silsoe $R e-$ search Institute, Wrest Park, Silsoe, Bedford MK45 4HS, UK, ${ }^{2}$ Aviagen Ltd, Newbridge, Midlothian EH28 8SZ, UK, ${ }^{3}$ David Filmer Ltd, Wascelyn, Brent Knoll, Somerset TA8 4DT, UK, ${ }^{4} 20$ De Bruce Road, Brompton, Northallerton, North Yorkshire DL6 $2 Q E, U K$

In commercial practice, broilers may deviate from their planned growth curve due to differences between planned and actual feed intake, disease, change in 
environmental conditions, genetic variability and the feed not being of the assumed composition. The aim of this research was to develop a prototype closedloop, model-based, fully automatic, real-time system for the control of broiler growth and nutrition for commercial use.

All of the experimental work was carried out on a commercial broiler farm with eight identical modern houses of 30000-40000 birds. Each house was fitted with a commercially available broiler nutrition management system, which automatically measured the feed intake and bird weight, and provided nutrition control by blending two feeds according to the specifications given by the human operator or our automatic growth and nutrition control system. Whole wheat was blended with a concentrate feed from as early as Day 5 and our control system operated from Day 14. A semi-mechanistic growth model was developed, based on established models and principles, in which growth is predicted from feed intake and feed composition (Emmans 1981, 1994). The controller first attempts to improve the prediction of the growth model on the basis of past data from the house it is controlling. It does this by optimizing a common digestibility parameter. The controller then determines the nutrition for the remainder of the growing period. It optimizes feed composition, and optionally the required feed intake, to minimize the Residual Mean Square Error (RMSE) between the target and predicted growth curves.

The model adaptation procedure gave excellent results for healthy birds. In all of the trials except one, the houses were disease free for the first 4 weeks. A significant number of houses then exhibited symptoms of coccidiosis. In a typical validation experiment, which included a step change in nutrition, the range of RMSE for the eight houses was 258$11927 \mathrm{~g}^{2}$ before adjustment for digestibility and $237-1178 \mathrm{~g}^{2}$ after. When operated as a closed loop, offline controller, updating the control variable three times per week, with a 24-h lag due to the logistics of the operation, results comparable with a human manager were attained. A fully automatic product has now been developed and is undergoing commercial testing on several farms.

This research is funded under the Defra LINK Sustainable Livestock Production Programme. The authors acknowledge the support of the industrial sponsors: Premier Farming Ltd., Stonefield Systems Ltd. and David Filmer Ltd.

Emmans, G. C. (1981). A model of the growth and feed intake of ad libitum fed animals, particularly poultry. In Computers in Animal Production, British Society of Animal Production Occasional Publication No. 5 (Eds G. M. Hillyer, C. T. Whittemore \& R. G. Gunn), pp. 103-110. Thames Ditton: BSAP.

Emmans, G. C. (1994). Effective energy: a concept of energy utilisation applied across species. British Journal of Poultry Nutrition 71, 801-821.
Weed populations and crop rotations: exploring dynamics of a structured periodic system. S. K. MERTENS $^{1}$, F. VAN DEN BOSCH ${ }^{1}$ AND J. A. P. HEESTERBEEK ${ }^{2} .{ }^{1}$ Biomathematics Unit, Rothamsted Research, Harpenden, Hertfordshire AL5 2JQ, UK, ${ }^{2}$ Faculty of Veterinary Medicine, University of Utrecht, PO Box 80151, 3508 TD Utrecht, The Netherlands

The periodic growing of a certain set of crops in a prescribed order, called a crop rotation, is considered to be an important tool for managing weed populations. Nevertheless, the effects of crop rotations on weed population dynamics are not well understood. Explanations for rotation effects on weed populations usually invoke the diversity of environments, caused by different crops, that a weed population encounters (e.g. Liebman \& Dyck 1993). Using a periodic matrix model, we have shown that the number of different crops is not the sole factor, and that the sequence of a given set of crops can play an important role (Mertens et al. 2002).

In the model, the weed population is structured by seed depth in the soil (i.e. the values for life history parameters vary according to the depth at which seeds are located in the soil), and ploughing moves seeds between layers. For illustration of concepts, we used parameter values thought to be characteristic for Polygonum persicaria growing in carrots (Crop A) and spring wheat (Crop B) in the Netherlands. We systematically examined the population growth rates for $P$. persicaria and their sensitivity to changes in parameter values for all rotations of 2 to 6 years based on Crops A and B. We included eight scenarios that differed in the effects of ploughing and seed survival over winter.

Differences between rotations could be striking. For example, assuming $100 \%$ winter survival, the weed population growth rate in the baseline rotation $\mathrm{AABB}$ was nearly $25 \%$ lower than in rotation $\mathrm{ABAB}$. The effect of a proportional change in seedling survival on the population growth rate (elasticity of the growth rate) was nearly $75 \%$ higher in the B years of rotation $\mathrm{ABAB}$ than in the $\mathrm{B}$ years of rotation AABB. Given a structured weed seed bank population subjected to a periodic environment, different sequences of a given set of crops will result in different population dynamics. Different sets of parameter values for each crop will only alter the particular values that the population growth rate and its associated sensitivities take. Different parameter values will not alter the conclusion that crop order will have an effect on weed population dynamics.

This work was carried out while SKM was working in the Crop and Production Ecology Unit at Plant Research International, The Netherlands and in the Crop and Weed Ecology Group at Wageningen University, The Netherlands. Funding for this work was from The Netherlands Ministry of Agriculture, Nature Conservation 
and Fisheries Programmes 342 (Organic Farming) and 343 (Weed Management and Control).

Liebman, M. \& Dyck, E. (1993). Crop rotation and intercropping strategies for weed management. Ecological Applications 3, 92-122.

Mertens, S. K. Van den Bosch, F. \& Heesterbeek, J. A. P. (2002). Weed populations and crop rotations: exploring dynamics of a structured periodic system. Ecological Applications 12, 1125-1141.

A decision support system to evaluate phosphorus pollution by dairy cows. E. KEBREAB, J. A. N. MILLS, L. A. CROMPTON AND J. FRANCE. School of Agriculture, Policy and Development, University of Reading, Reading RG6 6AR, UK

Phosphorus $(\mathrm{P})$ is a mineral essential to the dairy cow and needs to be supplied in sufficient quantites to optimize animal performance. However, dairy cows currently use less than $40 \%$ of dietary $\mathrm{P}$ intake and the rest is excreted mainly in faeces. Faecal $\mathrm{P}$ excretion can lead to $\mathrm{P}$ accumulation in the soil, leach into groundwater or cause eutrophication of surface waters due to run-off from agricultural land. The objective of this work was to produce a model to simulate $\mathrm{P}$ transactions in the animal in order to enable diets to be evaluated for their potential contribution to environmental pollution.

A mechanistic model of the rumen was developed by Dijkstra (1994), and this was extended to simulate $\mathrm{P}$ flows in the whole animal. The extended model is driven by inputs of nutrients and consists of 19 state variables representing $\mathrm{N}$, carbohydrate, fatty acid and microbial pools in the rumen and a further 11 ruminal and extra-ruminal $P$ pools. The ruminal $P$ pools include digestible, indigestible, bacterial and protozoal P. Extra-ruminal P pools include salivary, small intestinal digestible and indigestible, large intestinal digestible, indigestible and microbial, and blood P. The model was written in Digital Visual FORTRAN and various numerical integration methods are available, with a fourth order RungeKutta being the default option. The model is run until a steady state is achieved. A graphical user interface was developed using Visual Basic 6 that allows the user to input simply dietary details required by the model. After the model is run, it provides a summary of results showing $\mathrm{P}$ balance and an option to analyse data using plotting software.

The model was run for a $600 \mathrm{~kg}$, non-pregnant cow with average milk production of $20 \mathrm{~kg} / \mathrm{day}$. The amount of $\mathrm{P}$ excreted in faeces was linearly related to $\mathrm{P}$ intake when $\mathrm{P}$ intake alone was varied. However, increasing the energy density of the diet by $20 \%$ reduced faecal $\mathrm{P}$ excretion from $60 \%$ to $39 \%$ of $\mathrm{P}$ intake. This is mainly due to increased efficiency of utilization of digestible $P$ in the rumen and increased absorption from the small intestine. The model results showed that the type and amount of energy, and degradability and amount of $\mathrm{N}$ intake affects the extent to which $\mathrm{P}$ is excreted in faeces. The model can help to assess diets for their potential contribution to $\mathrm{P}$ pollution and suggest ways in which it can be mitigated.

This research was funded by Defra Agri-Environment (WA0320).

Dijkstra, J. (1994). Simulation of the dynamics of protozoa in the rumen. British Journal of Nutrition $\mathbf{7 2}$, 679-699.

Use of plant competition models to achieve an optimal balance between machine vision capability and weed treatment effectiveness. K. PHELPS ${ }^{1}$, R. J. REA$\mathrm{DER}^{1}$, C. M. ONYANGO ${ }^{2}$, A. C. GRUNDY ${ }^{1}$, J. A. MARCHANT ${ }^{2}$ AND L. R. BENJAMIN ${ }^{3}$. ${ }^{1}$ Horticulture Research International, Wellesbourne, Warwick CV35 9EF, UK, ${ }^{2}$ Silsoe Research Institute, Wrest Park, Silsoe, Bedford MK45 4HS, UK, ${ }^{3}$ Rothamsted Research, Harpenden, Hertfordshire AL5 2JS, UK

An automated mechanical weeding device guided by machine vision could achieve precision in the detection and subsequent removal of weeds. The system would need to offset undesirable effects of accidental crop damage against the desired effects of yield gain through removing competition from weeds. To allow the outcome of mechanical weeding scenarios to be simulated, a simple mechanistic competition model was extended to incorporate equations for the removal of weeds, either as whole plants or as partial plants. Linking this model with the output from a detection system provides a powerful tool (Reader et al. 2003) for quantifying the yield consequences of weeding where incomplete weed removal or crop damage may typically be experienced.

We use two weed-crop scenarios (Grundy et al. 2003) to demonstrate the trade-off between increasing the sensitivity of the detection system v. the possibility of, in doing so, misclassifying some crop plants as weeds and inadvertently removing them. The best parameter values to maximize crop and weed detection appeared relatively insensitive to time of image capture, weed density and crop species of similar growth habit. However, competition scenarios indicated that the detection system parameter settings to achieve optimum yields were sensitive to the competitive ability of the weed species. Importantly, linking the detection system with the competition model illustrated the principle that optimum yield may not necessarily be obtained by maximizing weed removal or minimizing crop removal.

This research was funded by the BBSRC.

Grundy, A. C., Onyango, C. M., Phelps, K., Reader, R. J. \& Marchant, J. A. (2003). Achieving an optimal balance between machine vision capability and weed treatment 
effectiveness using competition models. II. Application of the model. Weed Research, submitted.

Reader, R. J., Phelps, K., Onyango, C. M., Grundy, A. C., Marchant, J. A. \& Benjamin, L. R. (2003). Achieving an optimal balance between machine vision capability and weed treatment effectiveness using competition models. I. Modelling framework. Weed Research, submitted.

\section{STRATEGY: a decision support system for the long- term management of radioactively contaminated land. G. M. COX ${ }^{1}$, N. M. J. CROUT ${ }^{1}$ AND N. A. BERESFORD ${ }^{2} .{ }^{1}$ School of Life and Environmental Science, University of Nottingham, Nottingham NG7 $2 R D, U K,{ }^{2} C E H$, Merlewood, Grange-over-Sands, Cumbria LA11 6JU, UK}

After the release of radionuclides into the environment, the relevant authorities may have to make a series of complex decisions to ensure the safety of any affected human populations, and to reduce any resulting radiation doses as far as reasonably possible. These authorities must consider many factors including the specific radiological, agricultural, environmental, social and economic conditions in the affected area.

STRATEGY is being developed as a decision support tool to assist the selection of sustainable, long-term management and restoration strategies for radioactively contaminated land. Fundamental to the utility of the system is the spatial and temporal modelling of the transfer of long-lived radionuclides between the different compartments of the human food chain (soil, plants, animals and food products).

Plant uptake of radionuclides is predicted using a raster-based GIS database of soil characteristics in the affected area, combined with existing plant uptake models (Absalom et al. 2001; Müller \& Pröhl 1993). Spatially variable agricultural data (such as crop and livestock management practices) are then used to estimate the activity concentrations of common food products, and these are coupled with habits data in order to calculate the resulting ingestion doses of affected human populations.

Various agricultural countermeasures are incorporated within the model and these can be applied to try to mitigate against any dose received by the human population. The user can select manually which countermeasures are implemented, and the level of implementation, or the system can attempt to find the optimal selection of countermeasures and their respective implementation levels automatically. The optimization of countermeasure strategies is performed by the minimization of a target function that incorporates the cost of countermeasure implementation and the monetary cost of the collective dose received.

This research is funded by the European Commission, project number FIKR-CT-2000-00018.
Absalom, J. P., Young, S. D., Crout, N. M. J., Sanchez, A., Wright, S. M., Smolders, E., Nisbet, A. F. \& Gillett, A. G. (2001). Predicting the transfer of radiocaesium from organic soils to plants using soil characteristics. Journal of Environmental Radioactivity 52, 31-43.

Müller, H. \& PröHL, G. (1993). ECOSYS-87: a dynamic model for assessing radiological consequences of nuclear accidents. Health Physics 64, 232-252.

Estimating parameters of a stochastic grazing model. D. M. WALKER ${ }^{1}$, G. MARION ${ }^{2}$, D. L. SWAIN ${ }^{3}$, M. R. HUTCHINGS ${ }^{3}$, M. FRIEND ${ }^{4}$ AND D. A. ELSTON ${ }^{1} .{ }^{1}$ Biomathematics \& Statistics Scotland, The Macaulay Institute, Craigiebuckler, Aberdeen AB158QH, UK, ${ }^{2}$ Biomathematics \& Statistics Scotland, James Clerk Maxwell Building, The King's Buildings, Mayfield Road, Edinburgh EH9 3JZ, $U K,{ }^{3}$ Animal Biology Division, Scottish Agricultural College, West Mains Road, Edinburgh EH9 3JG, UK, ${ }^{4}$ School of Agriculture, Charles Sturt University, PO Box 588, Wagga Wagga NSW 2678, Australia We introduce a spatially explicit model that describes the foraging behaviour of grazing animals using simple stochastic rules. The model bases animal decisions to move to a new location on visual assessment of sward height and decisions to graze at a particular location depend on the local sward height and olfactory assessment of the faecal contamination (Arnold 1987; Hutchings et al. 1998; Marion et al. 2003). A key challenge raised by stochastic models of this type is the potential to estimate parameters in a statistically rigorous way. Here we describe a method of estimating the rate parameters of such a stochastic process using the computational statistical technique of reversible jump Markov chain Monte Carlo (MCMC) integration (Green 1995). The stochastic model is event driven and the cases of a completely observed process where all events are observed and a partially observed process where the history of events is incomplete are considered. The latter case requires consistent event history reconstructions using simulated realizations of the process to be proposed within a Metropolis-Hastings type algorithm (Gibson \& Renshaw 1998; O'Neill \& Roberts 1999). Numerical simulations are used to gain insight into the impact limited information has on the ability to provide quality parameter estimates via MCMC. Data from an experimental study of real animals are analysed to demonstrate the potential of the modelling approach taken.

Arnold, G. E. (1987). Influence of the biomass, botanical composition and sward height of animal pastures on foraging behaviour of sheep. Journal of Applied Ecology 24, 759-772.

Gibson, G. J. \& Renshaw, E. (1998). Estimating parameters in stochastic compartmental models using Markov chain methods. IMA Journal of Mathematics Applied in Medicine \& Biology 15, 19-40. 
Green, P. J. (1995). Reversible jump Markov chain Monte Carlo computation and Bayesian model determination. Biometrika 82, 711-732.

Hutchings, M. R., Kyriazakis, I., Anderson, D. H., Gordon, I. J. \& Coop, R. L. (1998). Behavioural strategies used by parasitised and non-parasitised sheep to avoid ingestion of gastrointestinal nematodes. Animal Science 67, 97-106.

Marion, G., Swain, D. L. \& Hutchings, M. R. (2003). Understanding Foraging Behaviour in Spatially Heterogeneous Environments. BIOSS Technical Report, Edinburgh.

O’Neill, P. D. \& Roberts, G. O. (1999). Bayesian inference for partially observed stochastic epidemics. Journal of the Royal Statistical Society A 162, 121-129.

Dairy farm system simulation for assessing climate change impacts on dairy production in Ireland. J. B. FITZGERALD, A. J. BRERETON AND N. M. HOLDEN. Department of Agriculture and Food Engineering (Bioresources Modelling Group), University College Dublin, Earlsfort Terrace, Dublin 2, Ireland

A program called GRASS_SIM has been developed to simulate grass production and utilization on a dairy farm. Previous work has indicated that by the middle of the present century, much of the eastern half of Ireland will experience serious summer drought (Holden \& Brereton 2002) and changes in land management are likely to be required. The present work was undertaken to provide the means to assess the viability of GRASS_SIM to predict the sustainability of the traditional grass-based system of milk production following climate change.

In GRASS SIM, grass production is simulated using an empirical grass growth model (Brereton et al. 1996) that takes account of the effects of level of nitrogen use and of soil water deficit. Utilization of grass is simulated by GRAZEDOWN, a mechanistic grazing model (Brereton \& Holden, in preparation). Animal feed demand is based on the metabolizable energy system for feeding dairy cows (MAFF 1975). Daily weather data are derived from monthly averages using a stochastic weather generator, SIMMETEO (Geng et al. 1988). The program incorporates tactical management responses to drifts in the balance between grass supply and demand. The program has been tested by simulating the system for milk production with spring-calving cows developed by the National Dairy Research Centre at Moorepark (O'Donovan 2000). GRASS_SIM was found to produce outputs that agreed closely with those of the Moorepark system.

The common system of milk production in Ireland is designed to minimize costs by maximizing the use of grazed grass. Cows calve in February so that the lactation coincides with the period of active grass growth. Concentrate feeding is limited to $600 \mathrm{~kg} / \mathrm{cow}$ so that over $90 \%$ of annual feed is home-produced from grass. Nitrogen fertilizer is the primary determinant of output, and the matching of stocking rate and nitrogen use is the main strategic issue in the system. The system is optimized when total silage production matches demand and the feeding of silage supplement during grazing is minimized. GRASS SIM has been used to optimize the Moorepark system for different geographical locations, which represent the range of climatic variations in Ireland. Because the system is dominated by grass, inter-annual fluctuations in grass growth (whether this leads to a feed surplus or a deficit) represent a major hazard that has to be managed by appropriate tactical interventions. Average grass mass/ha is used as the main criterion for initiating tactical management responses-removal of surplus grass as opportunity silage or feeding a silage supplement in a period of grass deficit. The optimized system for each location represents the average of a period of 30 years as generated by the weather generator. The results indicate that GRASS_SIM is capable of simulating dairy systems that are adapted to regional climate scenarios and thus it should be suitable for use in climate change impact prediction studies.

Brereton, A. J., Danielov, S. A. \& Scott, D. (1996). Agrometeorology of Grass and Grasslands for Middle Latitudes. Technical Note No. 197. Geneva: World Meteorological Organisation.

Geng, S., Auburn, J. S., Brandsetter, E. \& Li, B. (1988). A program to simulate meteorological variables: documentation for SIMMETEO. Agronomy Progress Report No. 204. Davis, CA: Department of Agronomy and Range Science, University of California.

Holden, N. M. \& Brereton, A. J. (2002). An assessment of the potential impact of climate change on grass yield in Ireland over the next 100 years. Irish Journal of Agricultural and Food Research 41, 213-226.

MAFF (1975). Energy Allowances and Feeding Systems for Ruminants. Technical Bulletin 33. London: HMSO.

O'Donovan, M. A. (2000). The Relationship between the Performance of Dairy Cows and Grassland Management. Ph.D. thesis, University College, Dublin.

A wheat canopy model linking leaf area and phenology. C. LAWLESS ${ }^{1}$, M. A. SEMENOV ${ }^{1}$ AND P. D. JAMIESON ${ }^{2} .{ }^{1}$ Biomathematics Unit, Rothamsted Research, Harpenden, Hertfordshire AL5 4SE, UK, ${ }^{2}$ New Zealand Institute for Crop \& Food Research, Private Bag 4704, Christchurch, New Zealand

SIRIUS (Jamieson et al. 1998) is a relatively simple and effective wheat growth simulation model. The empirical curve representing the development of leaf area index in SIRIUS was replaced by a more detailed model describing the development of leaf area in layers of the canopy. SIRIUS phenology (Jamieson et al. 1995) and final leaf number (Brooking et al. 1995) predictions were used to derive the timing of layer appearance and the number of layers. The development of the area in each layer was described by 
potential functions, representing how growth would proceed in the absence of future resource limitations. We propose that describing potential areas in this fashion is a straightforward way to describe the genetic control of the plant phenotype. Actual area achieved was derived from these potentials using simple limitation rules. Potential for future growth was updated according to the history of resource availability. Parameters in the model are now related in an understandable way to biologically meaningful characteristics, such as phyllochron and maximum achievable leaf layer area. The new model has been calibrated and evaluated against existing canopy data (Barraclough et al. 1989), and better agreement was found compared with the semi-empirical canopy development model in SIRIUS previously. The extra information contained in this new canopy model will allow SIRIUS to be used to simulate competition, disease development, risk of lodging and radiation interception under a wide range of management and environmental scenarios. Modelling these characteristics within a simulation model such as SIRIUS, which predicts yield well, allows the economic consequences of different canopy structures to be assessed. This will create a framework for the design of the optimal canopy ideotype to suit these scenarios.

This research was funded by Defra (AR0906). Rothamsted Research receives grant aided support from the BBSRC.

Barraclough, P. B., Kuhlmann, H. \& Weir, A. H. (1989). The effects of prolonged drought and nitrogen fertiliser on root and shoot growth and water uptake by winter wheat. Journal of Agronomy and Crop Science 163, 352-360.

Brooking, I. R., Jamieson, P. D. \& Porter, J. R. (1995). The influence of daylength on the final leaf number in spring wheat. Field Crops Research 41, 155-165.

Jamieson, P. D., Brooking, I. R., Porter, J. R. \& Wilson, D. R. (1995). Prediction of leaf appearance in wheat: a question of temperature. Field Crops Research 41, 35-44.

Jamieson, P. D., Semenov, M. A., Brooking, I. R. \& Francis, G. S. (1998). SIRIUS: a mechanistic model of wheat response to environmental variation. European Journal of Agronomy 8, 161-179.

\section{Development of a genetic epidemiological model to assess the dynamics of infection in livestock popu- lations. M. NATH, J. A. WOOLLIAMS AND S. C. BISHOP. Roslin Institute (Edinburgh), Roslin, Midlothian EH25 9PS, UK}

Our modelling aims to describe the transmission of infection through genetically defined livestock populations, and use these modelling techniques to assess disease control strategies. Specifically, a stochastic genetic epidemic model is developed to assess (i) the relative importance of different genetic control strategies and (ii) the effect of host genetic heterogeneity in controlling the transmission of microparasitic, e.g. viral or bacterial, infection. We assume two closed populations of intensively housed animals comprising individuals of same age and physiological status, with no disease-independent mortality or external intervention. The first population is genetically homogeneous, while in the second there are three genotypes corresponding to one locus with two alleles (having each allele frequency as 0.5 and in Hardy-Weinberg equilibrium) determining resistance to infection.

The transmission of microparasitic infection may be described by compartmental models (Anderson \& May 1992). A stochastic modelling approach was developed by MacKenzie \& Bishop (2001), comprising random sampling to determine the time until the next event and sampling to determine which permitted biological event occurs. The possible event types for the present model are: a susceptible animal $(S)$ becomes latently $(L)$ infected, a latently infected animals becomes infectious $(I)$, an infected animal recovers $(R)$ or dies as a result of infection, and an animal that has recovered loses immunity and becomes immunologically susceptible again. The inter-event time has mean: $1 /(\beta c S I+\sigma L+\gamma I-\varepsilon I+\omega R)$, where $\beta$ is the transmission coefficient for an animal and $c$ is the contact rate between animals (assumed to be 1 in the present case), $\sigma$ is the rate at which latent animals become infectious, $\gamma$ is the recovery rate, $\varepsilon$ is the disease-dependent mortality rate and $\omega$ is the rate of loss of immunity. The inter-event time may then be drawn from an exponential distribution as $-\ln (r) *$ (mean inter-event time), where $r$ is a random number in $[0,1]$. The parameter spaces investigated were: latent periods (1,2, 7, 15, 30 and 180 days), recovery periods $(1,2,5,10,20$ and 30 days), mortality rates $(0 \cdot 00,0 \cdot 02,0 \cdot 05,0 \cdot 10,0 \cdot 20$ and $0 \cdot 30 /$ day $)$ and days for loss of immunity $(7,15,30,60,120,180$ days). In the homogeneous population $\beta$ was $0.00001,0.00005$, $0.0001,0.0005,0.0007$ and $0.001 S / I$ per day. In the heterogeneous population, $\beta$ for heterozygous genotypes was the same as in the homogeneous population, with homozygous dominant and homozygous recessive genotypes being $50 \%$ lower and higher, respectively. A total of 5000 replicates were run for each combination of parameters in each population $(n=1000)$. Output included probabilities of no epidemic $(p)$, minor and major epidemics (major, if $>10 \%$ individuals infected and epidemic continued for more than 6 months without intervention), maximum epidemic severity and time of maximum severity. The basic reproductive ratio $\left(R_{0}\right)$ was estimated as $1 / p-1$.

Critical parameters controlling the transmission of infection and epidemic severity were $\beta$, essentially the resistance of susceptible hosts to infection, $\sigma$ and $\gamma$. Reducing these parameters can bring $R_{0}$ below 1, thus reducing the probability of a major epidemic to zero. Broadly similar results were obtained from the homogeneous and heterogeneous populations, but the heterogeneous population may contain very susceptible animals without leading to greatly increased 
disease risks. The results are particularly relevant to the development of strains of animals that have enhanced genetic resistance to specific infectious diseases, and for the interpretation of studies investigating resistance genes and disease control strategies.

The authors thank the BBSRC for financial support.

Anderson, R. M. \& May, R. M. (1992). Infectious Diseases of Humans: Dynamics and Control, First Edition. Oxford: Oxford University Press.

MacKenzie, K. \& Bishop, S. C. (2001). Developing stochastic epidemiological models to quantify the dynamics of infectious diseases in domestic livestock. Journal of Animal Science 79, 2047-2056.

Which traits promote persistence of feral GM crops? D. CLAESSEN ${ }^{1,2}$, C. A. GILLIGAN ${ }^{2}$, P. J. W. LUTMAN ${ }^{1}$ AND F. VAN DEN BOSCH ${ }^{1} .{ }^{1}$ Rothamsted Research, Harpenden, Hertfordshire AL5 2JQ, $U K,{ }^{2}$ Department of Plant Sciences, University of Cambridge, Cambridge CB2 3EA, UK

Transgenes in plants may affect life history traits such as seed survival, germination and growth (Wolfenbarger \& Phifer 2000). We use stochastic matrix population models to predict population-level consequences of transgene-induced life history changes (Caswell 2001). With this approach we can address important issues in risk assessment of transgenic crops like invasiveness and persistence, as well as fitness effects in case of introgression. We apply our method to oilseed rape, which persists as a weed inside and as feral patches outside cultivated fields. Like many other annual weeds, oilseed rape depends critically on disturbance. The associated inherent variability and unpredictability render deterministic models inappropriate (Claessen 2003). With a stochastic model we study population growth rate, elasticities and quasi-extinction times. In our model life history parameters subject to environmental stochasticity are germination, seedling survival and the production of dormant seeds. The latter is relevant for crops such as oilseed rape in which induced dormancy depends on soil conditions (Pekrun et al. 1997).

Our results indicate that changes in survival in the seed bank have the largest impact on population growth and persistence. Given a high disturbance rate, dormancy and to a lesser extent fecundity also contribute significantly. By considering known effects of transgenes on life history in oilseed rape, we conclude that the effect of transgenic oil-modifications on seed survival and dormancy (Linder \& Schmitt 1995) could slow population decline and thereby increase persistence of transgenic feral and volunteer populations. $B t$ transgenes increase performance through plant survival and fecundity (Stewart et al. 1997), which are predicted to have less impact on fitness. It will therefore depend to a large extent on the unintentional effects on seed survival and dormancy whether $B t$ transgenes increase or decrease fitness. Finally, predicted distributions of extinction times are highly skewed; most patches go extinct within a few years but some persist for decades.

Caswell, H. (2001). Matrix Population Models, Second Edition. Sunderland, MA: Sinauer Associates.

Claessen, D. (2003). Elasticity analysis of simple stochastic matrix models. Ecology, submitted.

Linder, C. R. \& Schmitt, J. (1995). Potential persistence of escaped transgenes - performance of transgenic, oilmodified Brassica seeds and seedlings. Ecological Applications 5, 1056-1068.

Pekrun, C., Lutman, P. J. W. \& Baeumer, K. (1997). Induction of secondary dormancy in rape seeds (Brassica napus L.) by prolonged imbibition under conditions of water stress or oxygen deficiency in darkness. European Journal of Agronomy 6, 245-255.

Stewart, C. N., All, J. N., Raymer, P. L. \& RamachanDRAN, S. (1997). Increased fitness of transgenic insecticidal rapeseed under insect selection pressure. Molecular Ecology 6, 773-779.

Wolfenbarger, L. L., \& Phifer, P. R. (2000). The ecological risks and benefits of genetically engineered plants. Science 290, 2088-2093.

Modelling predation as a counting process. J. S. FEN$\mathrm{LON}^{1}$ AND M. J. FADDY ${ }^{2} .{ }^{1}$ Horticulture Research International, Wellesbourne, Warwick CV35 9EF, $U K,{ }^{2}$ School of Mathematics and Statistics, University of Birmingham, Birmingham B15 2TT, UK

The standard procedure for determining the predatory capacity of an invertebrate is the functional response, essentially a bio-assay in which individual predators are given access to fixed numbers of prey for a given period. The outcome of such experiments renders a basic response curve, the parameters of which can be estimated by some form of regression (Juliano 2001). The approach to the problem adopted by most entomologists and ecologists has entailed the use of mechanistic models to interpret the data, although several recent papers have argued that the use of simple logistic regression is more appropriate (see Casas \& Hulliger 1994). Many of the published data sets suffer from over-dispersion (i.e. a tendency for the data to have a variance greater than that predicted by the binomial distribution) which itself may be a function of prey density.

In this presentation we offer some new models which model the variance as well as the mean. The beta-binomial (Morgan 1992) is a frequently used model for extra-variation, and we shall develop some variants that allow for dependency on prey density. A totally new model based on stochastic counting processes (Faddy \& Fenlon 1999) is also presented. These models are illustrated using a couple of examples: one classical result from the literature, and another that incorporates some extra complexity. Within each 
example models are compared and contrasted on a strict likelihood basis. The beta-binomial outperforms the binomial in all cases, while the counting process model is generally as good as the best beta-binomial model. It is argued that the counting process model provides deeper insights into the predation process than do other descriptive models.

This research is partly funded through DEFRA projects HH2401/3SX.

Casas, J. \& Hulliger, B. (1994). Statistical analysis of functional response experiments. Biocontrol Science and Technology 4, 133-145.

Faddy, M. J. \& Fenlon, J. S. (1999). Stochastic modelling of the invasion process of nematodes in fly larvae. Applied Statistics 48, 31-37.

Juliano, S. A. (2001). Nonlinear curve fitting. In Design and Analysis of Ecological Experiments (Eds S. M. Scheiner \& J. Gurevitch), pp. 176-194. Oxford: Oxford University Press.

Morgan, B. J. T. (1992). Analysis of Quantal Response Data. Boca Raton, FL: CRC Press/Chapman \& Hall.

\section{The evolution of pathogen-induced leaf shed. F. VAN} DEN BERG ${ }^{1,2}$. ${ }^{1}$ Biomathematics Unit, Rothamsted Research, Harpenden, Hertfordshire AL5 2JQ, UK, ${ }^{2}$ University of Reading, Department of Agricultural Botany, Whiteknights, Reading RG6 6 AS, UK

Even though it is well known that pathogen-induced leaf shed takes place in many plant systems (Bashan 1993; Nelson \& Campbell 1993) and to a certain extent affects crop yields (Shtienberg \& Dreishpoun 1991), the mechanisms behind this process are poorly understood. This topic was studied in an evolutionary ecology context to get a better insight into the underlying processes.

A size-structured plant population model was developed to study the effect of pathogen load on pathogen-induced leaf shed under different environmental conditions. The evolution of the leaf-shed rate was studied and the Evolutionary Stable Strategy (ESS) was determined for two scenarios: (i) a constant leaf shed strategy and (ii) an infection-driven leaf shed strategy.

For both a constant and an infection-driven leaf shed rate, a plant is capable of evolving an ESS leaf shed rate and the results were qualitatively similar for both situations.

The model's main result was that the amount of external and allo-infection (between-plant infection) both have a decreasing effect on the ESS leaf shed rate whereas the amount of auto-infection (within-plant infection) has an increasing effect on the ESS leaf shed rate. This difference is caused by the fact that only in the case of auto-infection, shedding leaves and therefore reducing the infection load early in life has benefits for the plant's future.

Under a low external disease pressure, adopting an infection-driven leaf shed strategy seems to be much more efficient than adopting a constant leaf shed strategy. This is because a plant adopting an infection-driven leaf shed strategy does not shed any leaves in the absence of infection, even when leaf shed rates are high. On the other hand, a plant adopting a constant leaf shed rate sheds exactly the same amount of leaves in the absence as in the presence of infection.

This research is funded by the Lawes Trust Fund and the BBSRC.

Bashan, Y. (1993). Symptom expression and ethylene production in leaf blight of cotton caused by Alternaria macrospora and Alternaria alternata alone and in combination. Canadian Journal of Botany 72, 1574-1579.

Nelson, S. C. \& Campbell, C. L. (1993). Disease progress, defoliation, and spatial pattern in a multiple-pathogen disease complex on white clover. Phytopathology 83, 419-429.

ShtienberG, D. \& Dreishroun, J. (1991). Suppression of Alternaria leaf spot in Pima cotton by systemic fungicides. Crop Protection 10, 381-385.

Effects of phosphorus intake on phosphorus flow in growing pigs: application and comparison of two models. M. SCHULIN-ZEUTHEN ${ }^{1}$, J. B. LOPES ${ }^{2}$, E. KEBREAB ${ }^{1}$, D. M.S. S. VITTI ${ }^{3}$, A. L. ABDALLA $^{3}$, M. DE L. HADDAD ${ }^{4}$, J. A. N. MILLS $^{1}$, L. A. CROMPTON ${ }^{1}$ AND J. FRANCE ${ }^{1}$. ${ }^{1}$ School of Agriculture, Policy and Development, University of Reading, Whiteknights, Reading RG6 6AR, UK, ${ }^{2}$ Universidade Federal do Piaui, Centro de Ciências Agrárias, Campus Universitário de Socopo, Teresina PI, Brazil, ${ }^{3}$ Animal Nutrition Laboratory, Centro de Energia Nuclear na Agricultura, Caixa Postal 96, CEP 13400-970, Piracicaba SP, Brazil, ${ }^{4}$ Universidade de São Paulo, Escola Superior de Agricultura Luiz de Queiroz, Departamento de Entomologia, Piracicaba SP, Brazil

Studies of phosphorus $(\mathrm{P})$ metabolism often involve balance trials and use of isotopes. When combined with mathematical modelling, calculation of flows between several pools becomes a possibility. A key objective of the study on pigs employing isotope and balance techniques reported herein was to apply and compare two models of $\mathrm{P}$ metabolism for resolving data generated by these techniques.

Two mathematical models were applied to analyse the data. The Vitti model (Vitti et al. 2000) was adapted for growing pigs from growing goats. The model describes P flows between four pools: gut, blood, bone and soft tissues. It was constructed on the principles of the law of mass conversion and the rate: state formalism and assumed to be in partial steady state. The Fernández model (Fernández 1995) describes $\mathrm{P}$ flows between gut, blood and bone. The model was constructed and resolved using experimentally determined linear relationships between model components and $\mathrm{P}$ intake and information 
from a balance study. Inputs to both models were $\mathrm{P}$ intake, $\mathrm{P}$ excretion in faeces and urine, total $\mathrm{P}$ content in bone and blood, as well as specific activities in bone and blood. The two models compared were similar in principle, although their aims and therefore calculations differed.

Ten growing pigs were allocated to five groups and offered five different levels of $\mathrm{P}$ in the diet. The calcium concentration was maintained at the same level in all five diets. Following a single dose injection of ${ }^{32} \mathrm{P}$ into the jugular vein, blood samples, faeces and urine were collected at 24-h intervals for 7 days. Samples of liver, heart, kidney, muscle and bone were also collected and total $\mathrm{P}$ and radioactivity in all samples were measured.

The two models agreed on absorption rates from gut to blood, while the flow from blood to gut increased more slowly with the Vitti model than with the Fernández model. Phosphorus incorporation into bone increased a little faster in the Vitti model. The Fernández model gave a decreasing reabsorption from bone, which in the Vitti model was uninfluenced by $\mathrm{P}$ intake. Although flows to and from bone differed, the models gave an identical increasing $\mathrm{P}$ net retention in bone with increasing intake.

Fernández, J. A. (1995). Calcium and phosphorus metabolism in growing pigs. III. A model resolution. Livestock Production Science 41, 225-261.

Vitti, D. M. S. S., Kebreab, E., Lopes, J. B., Abdalla, A. L., De Carvalho, F. F. R., De Resende, K. T., Crompton, L. A. \& France, J. (2000). A kinetic model of phosphorus metabolism in growing goats. Journal of Animal Science 78, 2706-2712. 